\title{
Research Status and Enlightenment of Teaching Evaluation of Teachers at Home and Abroad
}

\author{
Defu Shao \\ Office of Academic Affairs \\ Jiamusi University \\ Jiamusi Heilongjiang 154007
}

Hongwei Pan

Jiamusi University

Jiamusi Heilongjiang 154007

\author{
Xiaojun Ma \\ School of Mechanical Engineering \\ Jiamusi University \\ Jiamusi Heilongjiang 154007 \\ mjzx2009phd@163.com \\ Chunjiang $\mathrm{Li} *$ \\ Jiamusi University \\ Jiamusi Heilongjiang 154007 \\ jmslcj@sohu.com
}

\begin{abstract}
The teaching quality is the lifeline and the evaluation of it is the supervision and control of guaranteeing teaching quality. After analyzing the status quo of domestic and fore ign te achers' teaching quality evaluation, and studying on the features, types, subjects and indicator system of evaluation, this paper puts forward the necessity to build a teaching quality evaluation system that is supported by both teachers and students, which is of far-reaching significance for the improvement of teaching quality and the improvement of the quality of personnel training.
\end{abstract}

Keywords-teacher's teaching quality; evaluation system; research status, experience and inspiration

\section{INTRODUCTION}

The key to the quality of teaching depends on the effect of teachers' teaching. Therefore, evaluating teacher's teaching effect becomes an important content of teacher assessment, and it also offers strong guarantee for colleges to realize scientific management and improve teaching quality. Scientifically evaluating the performance of teachers, especially their teaching quality is of great importance to mobilize them to improve teaching methods so as to improve teaching quality, evaluate the teacher's duty performance, and ensure the full realization of college personnel training goal. At present, the evaluation of university teachers' teaching effectiveness has been widely carried out with diversified evaluation methods and a considerable number of evaluation index systems, and a great deal of achievements have been gained. However, as a very complicated task, it was affected and restricted directly or indirectly by many factors, influencing the ultimate effect of evaluation activities. To do well an evaluation will face many difficulties. Therefore, to conduct a scientific analysis of teacher-student linkage education evaluation activities, especially the analysis of the factors affecting the evaluation and the systematic analysis of the evaluation index system of the existing teacher-student evaluation of teaching, is of great importance to eliminate teachers' concerns and improve

Funding Projects: Heilongjiang Higher Education Teaching Reform Project:(SJGY20170573)and Jiamusi University Education and Teaching Research Project teaching efficiency and quality, and further improve student evaluation of teaching.

\section{Theoretical Study on The Evaluation of Teachers' TEACHING EFFECT}

\section{A. Study On The Feature Of Evaluation}

Scholars Zhang Yutian, Shen Yushun, and Zhang Zhuo believe that contemporary teaching evaluation has three major features: First, on its guiding ideology and purpose, it fully embodies the educational function of evaluation as it is devoted to promoting the overall development of student's character. Second, as to the function of evaluation, it focuses on the educational functions. Third, in the evaluation type, it emphasizes the implementation of formative evaluation. The three basic strategies of teaching evaluation: First, establish a correct concept of teaching evaluation, including the ideas that the teaching evaluation serves and promotes human development, and serves and promotes education and teaching; second, take an objective view of the management function of teaching evaluation; third, we must give play to the educational function of teaching evaluation [1].

\section{B. Study on the Categories of Teaching Evaluation}

Bloom, according to the different time and the role played by evaluation in teaching, divides the teaching evaluation into three categories: diagnostic evaluation, formative assessment and summative assessment. At present, there is a research trend at home and abroad "to achieve the transition from summative assessment to process evaluation”, which is resulted from the fact that summative evaluation is utilitarian in nature with the purpose of rating or grading teachers as it consistently uses scores as a measure of good or bad, so it cannot achieve the adjustment and feedback functions of evaluation. Otherwise, it will exert a series of negative effects, and be further developed in people's eyes into useless evaluation. Whereas, the formative evaluation emphasizes the function of evaluation and requires that the results of the evaluation be fed back to the teacher with

*Correspondence Author: Li Chunjiang(1970-),master tutor 
the purpose to modify and improve the function of the teacher's teaching program by evaluating to control the teaching process [2].

\section{Study on the Significance of Teaching Evaluation}

As a conscious and purposeful self-conscious activity of human beings to train people, teaching activities cannot proceed without evaluation. The significance of teaching effectiveness evaluation can be illustrated from five aspects: First, incentive effect. The results of the evaluation may provide feedback for the one being evaluated, and he may use the information to improve work and carry forward his achievements. The second is regulation. From the information theory point of view, the teaching process is a process of information input, transformation, output, feedback, and adjustment. Teaching evaluation is a process of adjusting the information required for teaching activities in an organized way. It enables teachers to make necessary, appropriate and timely adjustments to the original teaching design according to the feedback from students so as to keep a dynamic balance within teaching system by controlling small changes and achieve the best teaching results. The third is the diagnosis, that is, provide consultation service for teachers to take effective teaching remedial measures. The fourth is management. As a kind of value judgment, teaching evaluation can objectively evaluate the teaching effect, thus providing a basis for teachers' appraising and promotion. The fifth is the development. The analysis and effective use of evaluation results can provide first-hand information for teaching reform.

\section{Study on the Subject of Teaching Evaluation}

There are many ways to evaluate teachers' teaching effects, such as teacher self-evaluation, peer evaluation, leader evaluation, expert evaluation, and student evaluation of teachers. In a sense, teaching evaluation is a special utility relationship action between the subjective needs of the evaluator and the object's objective attributes. Correctly grasping the relationship between subject and object of teaching evaluation, attaching great importance to listening to the views and opinions of the subject and object in the education evaluation and stimulating the enthusiasm and initiative of the subject and the object to participate in the evaluation, are the basis of the value orientation of education evaluation, and also a basic premise to improve the reliability and validity of evaluation. Due to the differences in the role of the evaluation subject, their role in evaluation should be different. Each evaluation method and its result is only a part of the evaluation of teacher's teaching effect, and cannot be equal to all of the teacher's teaching effect.

\section{RESEARCH ON EVALUATION INDEX SySTEM OF TEACHERS' TEACHING EFFECT}

\section{A. Research on the Teaching Value}

There are many theoretical studies abroad on this subject. For example, Syracuse University in the United States puts forward seven qualities of effective teaching: good organization of subject content and curriculum, effective communication, familiarity with and love of subject content and teaching, positive attitude toward students, fairness in examinations and grading, flexible teaching methods, and appropriate outcome of students' learning. The six key principles that Ramsden has come up with for good teaching are clearly explaining complex subject materials and sparking students' interest in learning, caring and respecting students and students' learning; evaluating students' learning appropriately and offering useful feedback, posing clear learning goals and proper challenges to students, helping students to learn independently, make learning strategies and actively participate in learning: learning from the students' learning situation. In addition, Bridges \& Gumport summed up six signals of inefficient teaching: failure to maintain classroom discipline; failure to treat students correctly; ailure to achieve the desired teaching effects; lack of knowledge of the subject; failure to effectively impart subject knowledge; failure to reasonably adopt the opinions of others. These theoretical studies are important value standards for the formulation of an evaluation index system for teaching effectiveness in China [3].

\section{B. Research on the Principle for the Design of Index System}

Research shows that the general principles for the design of the index system should meet the following conditions: consistency with the objectives (mainly the consistency of various specific indicators within the system and goals), direct measurability (the content specified by the indicators can be directly measured by observation to obtain a clear conclusion), the independence of the indicators within the system (the indicators in the same level must be incompatible), the completeness of the index system (the comprehensiveness of the index system), comparability (Indicators must reflect the common attributes of the objects being evaluated for easy comparison) and acceptability (conforming to the actual level of educational development, evaluating according to indicators).

In our country, there are various views toward the development of teachers' teaching effect evaluation index system. First, the evaluation system should be considered together with the purpose of evaluation; second, the important point of evaluation system should be the performance of teaching; third, we should select the sensitive indicators that are able to reflect the performance of teachers' work; fourth, we should focus on the rigid indicators to improve operability; fifth, we should regard the teaching and education as the main content of the evaluation. The proposal and discussion of these views have played a role in the development of a scientific teaching evaluation index system.

\section{Research on the Content of Index System}

There are two representative index systems in foreign countries. One is Teaching Quality Index raised by Meeth $L \cdot R \cdot$, which mainly divided the teaching quality into the media indicator during the teaching process (12 items in total) and the ultimate indicator of its effect (9 items in total). Instead of grasping it in all respects, Meeth attached more importance to the essence of teaching process, which means a particular cognitive process that under the teachers' guidance and based on students' existing experience. What's more, the evaluation indicators focus on the reaction of students rather than minor 
issues. Another is the Teaching Evaluation Index presented by Babansky, an educator of Soviet Union. Babansky sets indicators from the following nine aspects: the understanding of disciplines; the skills to evaluate the quality of knowledge, ability and faculty; the capability to make a work plan; the skills for effective completion of plans; skills to develop an interest in the subject; the connection between different subjects: treating students according to their aptitude; cultivation of students' general learning skills and competence : an understanding of the principles of educational psychology for students. To evaluate the teaching effect, he outlined the research of teaching and made a four-level scorching standard, which is helpful to its operability [4].

The Chinese scholar Zhang Yutian, through the research on the evaluation of teaching effectiveness of foreign teachers, combining with the teaching reality, has proposed some essential aspects of evaluation system of teaching quality, including practical teaching objectives, active students' participation; emphasis on the cultivation of student ability; highlighting the major points and making difficult points accurate; lively and effective teaching means: focusing on concept and principle teaching, system knowledge teaching: with simple and concise expression. Besides, other domestic scholars have conducted researches on the quality of evaluation indexes system. Wang Jinmei carried out a reliability analysis of his school's evaluation program in the article "Reliability Analysis on the Design Scheme of Teaching Quality Evaluation in Ningxia University". Liu Junshan and Meng Wanjin proposed in the article "On the Quality of Higher Education Evaluation Index System" that the quality of the evaluation index system includes both design quality and application quality, and they regard its reliability, validity, applicability as the measurement of evaluation indexes system.

\section{Research on Students' Evaluation of Teaching}

The importance of students' evaluation of teaching has been widely recognized. The British educators Williams and Blackstone said: 'The student's assessment of the teaching should be conducted regularly"; Egong Guba and Yvonna Session Lincoln, the founders of the "fourth generation education evaluation" that emerged in the United States in the 1980s, believed that "evaluation should be the process by which all those involved in the evaluation, especially the evaluators and their partners, interact and work together to construct a unified viewpoint." Some of the world's leading educators, such as Marsh Auvert also highly appreciated the importance of student evaluation; China also held that the principle of democracy is the significant in education evaluation [5].

In the study on the consistency of student assessments conducted in China, Wei Hong (from Peking University) concluded that as long as the number of students participating in the evaluation is sufficient, the students' assessment of teaching has a high degree of consistency. She fully affirms the significance of students' teaching assessments. Another view is that student evaluation is invalid, and Greenwald is a representative of this view. Greenwald made statistics on relevant papers published in the United States during the 25 years from 1971 to 1995 based on a psychological database.
The results show that from 1971 to 1980 , there were more studies that considered invalid and biased than valid about students' evaluations of teaching.

In 1985, colleges and universities in our country carried out the assessment of classroom teaching quality and implemented peer experts and student evaluation of teaching. Since 1987, with the increasing standardization of the title evaluation for teachers, many colleges and universities have placed higher and higher requirements on teaching, and student evaluation of teaching activities has become widespread. In the early 1990s, Tsinghua University and Peking University began to implement the undergraduate student evaluation of teaching, followed by Harbin Institute of Technology, Huazhong University of Science and Technology, Shanghai Normal University and Fudan University in the late 1990s.

\section{CONCLUSION}

To sum up, we have found that the theory and practice of teaching effectiveness evaluation of university teachers have been extensively carried out both at home and abroad, which has played a significant role in promoting education reform, improving the quality of education, and strengthening the teaching staff. At the same time, we should also recognize that as a subsystem of the education evaluation system, the depth and breadth of the research needs to be further improved. The issue of students' evaluation of education has always been controversial with many theoretical analyses but no corresponding empirical research. The reliability and validity of students' evaluation of teaching, the analysis of the factors affecting student evaluation, how to reduce the deviation of students' evaluation of teaching to achieve high quality evaluation all need to be oriented toward students, and further studies should be conducted from an empirical perspective. Since the reform and opening up, a considerable number of teaching qualities evaluation systems have been established in China. After years of practice, a relatively complete indicator system has been formed. However, in the current era of knowledge economy, as society is constantly changing, the evaluation index system we have formulated, and its connotation, must also meet the requirements of the times and society. This is a question worthy of our consideration.

\section{REFERENCES}

[1] Yu Jian, Han Yan, Liang Zhixing. Research on Multidimensional Classroom Teaching Quality Evaluation System of Civil Aviation University of China[J].Higher Education Development and Evaluation,2018,34(02):63-72+105-106.

[2] Hu Tao, Zhao Yan, Qi Xiuxiang. Explo ration and Practice of University Teachers' Teaching Development and Evaluation System under the Background of "Double First-rate": A Case Study of Zhengzhou University [J].Higher Education Forum,2018(03):54-57.

[3] Zhang Yu, Shen Yujie, Duan Qiwei. Research on the Status Quo and Countermeasures of Classroom Teaching Quality Evaluation in Colleges and Universities [J].Education Forum,2018(09):28-29.

[4] Zhang Jiarong. The Hot Fields and Frontier Themes of Teaching Research on University Teachers in China in the Past Ten YearsBased on the Keyword Co-occurrence Analysis of the Documents Cited by CNKI in 2006-2016 [J].Modern Education Science,2018(02):115-121.

[5] Hang Lanlv. Comment on Evaluation of University Teachers' Teaching Quality [J].Jiangsu Science \& Technology Information,2018,35(03):5759. 